\title{
Sưstalinable Chemistry\& Engineering

\section{Water and Carbon Dioxide: Green Solvents for the Extraction of Collagen/Gelatin from Marine Sponges}

\author{
Alexandre A. Barros, ${ }^{\dagger, \ddagger}$ Ivo M. Aroso, ${ }^{\dagger, \ddagger}$ Tiago H. Silva, ${ }^{\dagger, \ddagger}$ João F. Mano, ${ }^{\dagger, \ddagger}$ Ana Rita C. Duarte, ${ }^{*}, \dagger$
} and Rui L. Reis ${ }^{\dagger, \ddagger}$

${ }^{\dagger}$ 3B’s Research Group - Biomaterials, Biodegradables and Biomimetics, University of Minho, Headquarters of the European Institute of Excellence on Tissue Engineering and Regenerative Medicine, AvePark, 4806-909 Taipas, Guimarães, Portugal

${ }^{\ddagger}$ ICVS/3B’s - PT Government Associate Laboratory, Braga, Guimarães, Portugal

ABSTRACT: Marine sponges are extremely rich in natural products and are considered a promising biological resource. The major objective of this work is to couple a green extraction process with a natural origin raw material to obtain sponge origin collagen/gelatin for biomedical applications. Marine sponge collagen has unique physicochemical properties, but its application is hindered by the lack of availability due to inefficient extraction methodologies. Traditional extraction methods are time consuming as they involve several operating steps and large amounts of solvents. In this work, we propose a new extraction methodology under mild operating conditions in which water is acidified with carbon dioxide $\left(\mathrm{CO}_{2}\right)$ to promote the extraction of collagen/gelatin from different marine sponge species. An extraction yield of approximately $50 \%$ of collagen/gelatin was achieved. The results of Fourier transformed infrared spectroscopy (FTIR), circular dichroism (CD), and differential scanning calorimetry (DSC) spectra suggest a mixture of collagen/gelatin with high purity, and the analysis of the amino acid composition has shown similarities with collagen from other marine sources. Additionally, in vitro cytotoxicity studies did not demonstrate any toxicity effects for three of the extracts.

KEYWORDS: Green solvents, Extraction, Collagen, Gelatin, Marine sponges, Carbon dioxide, Water, Natural products

\section{INTRODUCTION}

Sustainable development relies not only on the development of novel processes but also on the use of alternative sources of raw materials, which decrease dependence from fossil fuel resources. In this sense, the sea provides a plentiful resource of potential new products for society including biomaterials. ${ }^{1,2}$

In the past decade, comprehensive manuscripts ${ }^{3}$ indicate that sponges (Porifera) are the most promising avenue for blue biotechnology, and their leading role within marine biotechnology stems from their long evolutionary history. These sponges are particularly rich in collagen, which is one of the most important and abundant proteins in the human body, with 20 genetically distinct forms known today. The current industrial demand for collagen is up to 326.000 tons per year ${ }^{4}$ for different fields of application, including alimentary, cosmetics, pharmaceutical, and biomedical. ${ }^{5-7,2,8}$

The advantages of the use of collagen include the fact that it is highly abundant in nature, nonantigenic, biodegradable, nontoxic, and biocompatible.' However, there are some constrains hindering the development of new products. Nowadays, $98 \%$ of the collagen is of mammalian origin, for instance, from calf skin and bone. These carry a high risk of disease transmission such as bovine spongiform encephalopathy, as well as social and/or religious constraints. ${ }^{10,11}$ Both Judaism and Islam forbid the consumption of porcine-derived products, while Hindus do not consume bovine-related products.

Aiming to overcome these drawbacks, alternative sources have been suggested, such as collagen from marine sources, including jellyfish, ${ }^{7}$ fish scales ${ }^{12}$ and skin, ${ }^{13}$ cuttlefish skin, ${ }^{14}$ and starfish. ${ }^{15}$ Particularly, sponge collagen has unique physicochemical properties ${ }^{16-18}$ and is a promising resource, but sponge collagen is not available in large quantities because of the lack of efficient extraction methodologies.

Traditionally, marine collagen/gelatin can be isolated from marine resources after acid, base, or enzymatic treatments. For sponges, a treatment with a complex Tris- $\mathrm{HCl}$ buffer solution $(\mathrm{pH}$ 9.5, $10 \mathrm{mM}$ EDTA, $8 \mathrm{M}$ urea, and $100 \mathrm{mM} 2-$ mercaptoethanol) is commonly proposed, ${ }^{1,19}$ but such methods are generally time consuming as they involve several operating steps and have low selectivity and low extraction yields. ${ }^{20}$ Furthermore, they require the use of large amounts of solvents. ${ }^{21}$ Environmental concerns and strict legislation on the use of volatile organic solvents are forcing chemical industries to move toward the application of alternative processing methodologies, which comply with the green chemistry philosophy. Chemical industries have been moving

Received: September 29, 2014

Revised: December 2, 2014 
toward the development of innovative processes as the awareness that sustainable development is becoming mandatory and essential for their competitiveness. ${ }^{22}$

The major objective of this work is hereafter the exploitation of a new extraction process, using water and carbon dioxide as solvents with a natural origin raw material to obtain sponge origin collagen/gelatin. To the best of our knowledge, it is the first time that this approach is reported in the literature. We propose, hereafter, a new extraction methodology for the extraction of acid soluble collagen/gelatin, which normally denatures at high temperatures (human collagens) ${ }^{23,24}$ under mild operating conditions, in which water is acidified with carbon dioxide to promote the extraction of collagen/gelatin from different marine sponge species.

\section{EXPERIMENTAL SECTION}

Materials. Sponge samples of the species Thymosea sp. were collected in the Atlantic Ocean in the Azores and were kindly provided by Joana Xavier (Azores University, Portugal). Samples of Chondrila nuculla were collected in the Mediterranean Sea. Chondrila nuculla from Alassio was grown in aquaculture, while Chondrila nuculla from Portofino is the wild type. Samples of Chondrosia reniformis were collect on the Israeli coast. The species were kindly provided frozen or freeze-dried by Ronald Osinga (Porifarma, The Netherlands), Micha Ilan (Tel Aviv University, Israel), and Antonio Sarà and Martina Millanese (Studio Associato GAIA, Italy).

All further reagents were high quality reagent grade chemicals for laboratory use (chemicals meet the specifications of the American Chemical Society, ACS) and were used as received.

Collagen/Gelatin Extraction. Marine sponges (Thymosea sp. (TIM), Chondrosia reniformis (CR), Chondrila nuculla, Alassio (ConAL), and Chondrila nuculla, Portofino (ConPF)) were ground in small pieces. Five grams of sponge material was weighed and washed with distilled water overnight to remove salt and any contaminants present and were then were lyophilized. Afterward, the samples were placed in a high pressure vessel $\left(30 \mathrm{~cm}^{3}\right)$, and $10 \mathrm{~mL}$ of distilled water was added. The vessel was heated to $37^{\circ} \mathrm{C}$. The system was pressurized with carbon dioxide to $50 \mathrm{bar}$. The extraction was performed in batch mode for $16 \mathrm{~h}$. After this time, the high pressure vessel was rapidly depressurized. The extract obtained was filtered with a $0.45 \mu \mathrm{m}$ filter and frozen. Collagen/gelatin powder was obtained after freeze-drying of the extracts.

Characterization of Marine Sponge Collagen/Gelatin. Extraction Yield and Collagen/Gelatin Quantification. The yield of extraction was quantified as the ratio of dry extract obtained per weight of initial dry sample. The quantification of collagen/gelatin on the different extracts was performed using the Sircol assay kit. The Sircol assay is a dye-binding method specific for the analysis of collagen/ gelatin. The determination of collagen/gelatin was carried out according to the protocol described by the manufacturer (Sircol, Soluble Collagen Asay, Biocolor, Life Science Assays, U.K.).

Scanning Electron Microscopy. The powder obtained from the different extractions was analyzed by a Nova NanoSEM 200 scanning electron microscope (SEM). The samples were fixed by mutual conductive adhesive tape on aluminum stubs and covered with gold using a sputter coater prior to microscopic analysis.

Fourier Transform Infrared Spectroscopy. Fourier transform infrared spectroscopy (FTIR) spectra of the extracts were obtained with a Shimadzu-IR Prestige 21 spectrometer in the spectral region of $4000-800 \mathrm{~cm}^{-1}$ with resolution of $2 \mathrm{~cm}^{-1}$ as the average of 32 individual scans. The samples were analyzed in $\mathrm{KBr}$ pellets.

Circular Dichroism. Circular dichroism (CD) measurements of the extracted material were performed using a Jasco Model J-865 spectropolarimeter (Jasco, U.K.) using a quartz cylindrical cuvette (Hellma, Germany) with a path length of $0.1 \mathrm{~mm}$. The cuvette was filled with $150 \mathrm{~mL}$ of sample $(0.01 \mathrm{~g} / \mathrm{mL})$ for each measurement. CD spectra were obtained by continuous wavelength scans (average of three scans) from 180 to $260 \mathrm{~nm}$ at a scan-rate of $50 \mathrm{~nm} / \mathrm{min}$. The samples were equilibrated for $1 \mathrm{~h}$ at room temperature before the $\mathrm{CD}$ spectra were acquired.

Differential Scanning Calorimetry. Differential scanning calorimetry experiments were carried out using a DSC Q100 equipment (TA Instruments, U.S.A.). The experiments were conducted under a nitrogen atmosphere on samples $(5-10 \mathrm{mg})$ packed in aluminum pans. The samples were heated at a constant heating rate of $5{ }^{\circ} \mathrm{C} / \mathrm{min}$ from 0 to $90{ }^{\circ} \mathrm{C}$, followed by an isothermal period at $90{ }^{\circ} \mathrm{C}$. The samples were then cooled at the same rate to the initial temperature.

Amino Acid Analysis. The amino acid content was determined by quantitative amino acid analysis using a Biochrom 30 (Biochrom Ltd., Cambridge, U.K.). ${ }^{22}$ Briefly, the samples were hydrolyzed and separated by an ion exchange column. After postcolumn derivatization by ninhydrin, the samples were analyzed at two wavelengths: 440 and $570 \mathrm{~nm}$. An internal standard of norleucine was used to determine the concentrations of amino acids in the sample.

Isoeletric Point Determination. The isoelectric point of the samples was determined following a titration protocol described in the literature. ${ }^{24}$ For each extract, $10 \mathrm{mg}$ of collagen/gelatin was dissolved in $6 \mathrm{~mL}$ of Milli- $\mathrm{Q}$ water. Each sample was titrated with a solution of $0.02 \mathrm{~N} \mathrm{NaOH}$ and with a solution of $0.02 \mathrm{~N} \mathrm{HCl}$. The $\mathrm{pH}$ was registered ( $\mathrm{pH}$ meter, 3510 Jenway), and the resulting $\mathrm{pH}$ values were plotted versus the amount of $\mathrm{NaOH}$ and $\mathrm{HCl}$. The titration range was from $\mathrm{pH} 2$ to 12 . All experiments were performed at room temperature.

Gel Permeation Chromatography-Size Exclusion Chromatography. The determination of the molecular weight of the samples was carried out by size exclusion chromatography (GPC-SEC). Briefly, 1 $\mathrm{mg}$ of extract was dissolved in $1 \mathrm{~mL}$ of an aqueous solution of sodium nitrate $0.2 \mathrm{M}$ containing $0.02 \%$ of sodium azide. The solutions were filtered through a $0.22 \mu \mathrm{m}$ membrane and analyzed on a size exclusion chromatograph (Viscotek TDA 305) equipped with three detectors: light scattering, refractive index, and viscometer. Elution was performed at $30{ }^{\circ} \mathrm{C}$ using a flow rate of $1 \mathrm{~mL} / \mathrm{min}$ of the following eluents: aqueous solution of sodium nitrate $0.2 \mathrm{M}$ containing $0.02 \%$ sodium azide. The column set was composed by a guard precolumn Aq. Guard col $50 \mathrm{~mm} \times 6.0 \mathrm{~mm}$ (Viscotek) and a PLaquagel-OH mixed $8 \mu \mathrm{m}$ ( $300 \mathrm{~mm} \times 7.5 \mathrm{~mm}$, Polymer Laboratories).

In Vitro Cytotoxicity. The cytotoxicity of the extracts was assessed on bioreduction of a novel tetrazolium compound, 3-(4,5-dimethylthiazol-2-yl)-5-(3-carboxymethoxyphenyl)-2-(4-sulfofenyl)-2H-tetrazolium (MTS) (cell titer 96 aqueous solution cell proliferation assay, Promega, U.S.A.). MTS assay was measured in accordance with ISO/ EN 10993 Part 5 guidelines ${ }^{27}$ using an immortalized mouse lung fibroblasts cell line (L929 cell line) purchased from the European Collection of Cell Cultures. Briefly, $1.5 \times 10^{4}$ cells $/ \mathrm{mL}$ were cultured in a 48 well plate in Dulbecco's modified Eagle's medium, supplemented with $10 \%$ fetal bovine serum (Alfagene, U.S.A.) and $1 \%$ antibiotic/antimycotic solution (Gibco, U.K.) for 24 h. At this time, medium was replaced by the collagen/gelatin solutions, with a concentration of $1: 15 \mathrm{~m} / \mathrm{v}$ (collagen solution:medium culture). Latex was used as positive control for cell death, and cell culture medium was used as a negative control representing the ideal situation for cell proliferation. Cell viability was evaluated by assessment of cell metabolic activity using the MTS assay after $72 \mathrm{~h}$ in culture. The bioreduction of MTS yields a water-soluble brown formazan product. This was quantified by UV-spectroscopy, reading the formazan absorbance at $490 \mathrm{~nm}$ in a microplate reader (Synergy HT, Bio-Tek Instruments, U.S.A.).

Statistical Analysis. Statistical analysis of the data was performed using IBM SPSS Statistics Version 20. Normality was verified by the Shapiro-Wilk test. Normal distributed data were then analyzed using one-way ANOVA with a Bonferronís post-test. When normality was not observed, a nonparametric test, namely, Kruskall-Wallis test was performed. Differences between the groups with $p<0.05$ were considered to be statistically significant. 


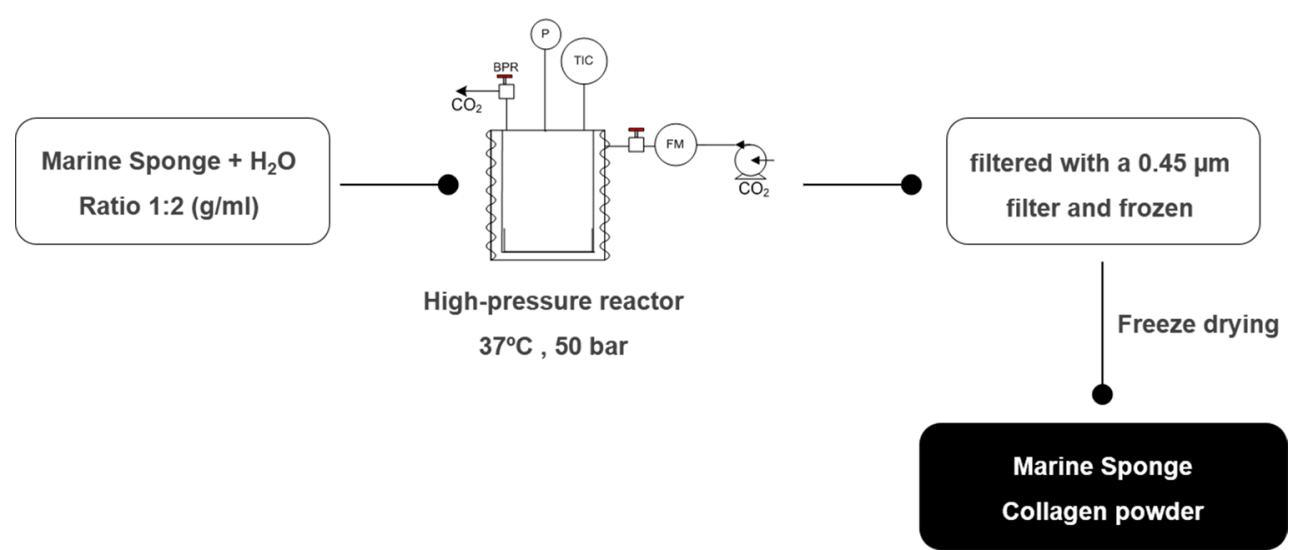

Figure 1. Schematic representation of the extraction procedure for marine sponge collagen/gelatin.

Table 1. Extraction Yield and Collagen/Gelatin Content on the Different Extracts

\begin{tabular}{|c|c|c|}
\hline source & gram extract/100 g sample ${ }^{a}$ & collagen/gelatin content $(\%)^{b}$ \\
\hline Thymosea sp. & 16.6 & 82 \\
\hline Chondrosia reniformis & 11.6 & 36 \\
\hline Chondrilla nuculla (Alassio) & 9.0 & 54 \\
\hline Chondrilla nuculla (Portofino) & 17.3 & 82 \\
\hline
\end{tabular}

${ }^{a}$ Values are indicated as a percentage of gram of collagen/gelatin per gram of wet tissue. ${ }^{b}$ Assessed by Sircol collagen quantification kit.

\section{RESULTS AND DISCUSSION}

Marine origin collagen/gelatin has been reported to be a great promise, but so far, there has been a gap between the scientific interest and the wide industrial application of this source of collagen/gelatin

Extraction. Different papers in the literature report the possibility to solubilize a fraction of collagen from different sources in acidic solutions, most of which are dilute acetic acid solutions, but these methods in marine sponges report low yield around $2 \% .{ }^{25}$ The procedures, however, do not lead to high yields of extraction, and the process requires several postoperation steps for the purification of the products. In this work, we propose the use of water acidified with carbon dioxide at $50 \mathrm{bar}$ to extract collagen/gelatin from the three species of marine sponges mentioned. In Figure 1, a schematic representation of the extraction procedure is represented.

Extraction Yield and Collagen/Gelatin Content. The quantification of the extraction yield was calculated as the mass of extract obtained per gram of sponge extracted. The extraction yields are presented in Table 1 .

In our study, results demonstrate that the lowest extraction yields were obtained for the Chondrilla nuculla (Alassio) sponge, and the highest yield was obtained from Chondrilla nuculla (Portofino). The results obtained are significantly higher than the ones presented for example by Addad and coworkers, who report the extraction of collagen from different organs of jellyfish. ${ }^{7}$ A careful comparison with the data from the literature however has to be carried out. In most cases, it is not clear whether the authors refer to the concentration of collagen in the extracts or in fact the amount of extract per weight of raw material. Regarding the extraction of the acid-soluble fraction from marine sponges from dilute acetic acid solutions, the proposed technology represents an improvement of nearly $30 \%$ in extraction yield. ${ }^{1,4,20}$ Besides the determination of the extraction yield, it is also important the quantification of the collagen/gelatin present in the extracts. The quantification of the amount of collagen/gelatin present in each extract was performed using a specific detection kit (Sircol assay kit), which revealed that the extracts recovered from Thymosea sp. and Chondrilla nuculla (Portofino) present a considerable high value of collagen/gelatin near $82 \%$. Considering that the collagen/ gelatin content of these species may vary from 30 to $40 \mathrm{wt} \%{ }^{1}$ the extraction performed represents hereafter an extraction yield of approximately $50 \%$ of the collagen/gelatin present in the sponge. Hence, the proposed technology for the extraction of marine sponges could be a valuable source of collagen/ gelatin for industrial exploitation. Such industrial exploitation is also dependent on the sustainability of the raw material, which in the case of marine sponges can be addressed by aquaculture. The obtained results indicated that the amount of collagen/ gelatin extracted from the wild sponge (ConPF) is about three times the amount extracted from the cultured one (ConAL). However, the current study did not account for the time at which marine sponges were collected, and the sustainability can be only correctly assessed with a study over time (covering different seasons) and embracing multiple sponge generations.

Morphological Analysis of the Extracts. The morphology of the obtained powder was observed by scanning electron microscopy, and the respective images are presented in Figure 2. From the images presented, it is noticeable that the typical fibrillar structure of collagen/gelatin was not observed in any of the samples obtained. However, nodular collagen has been reported in the literature in a work by Heinemann et $\mathrm{al}^{19}$ and Pozzolini et $\mathrm{al}^{18}$ in which collagen was extracted from Chondrosia reniformis.

Chemical Characterization of Extracts. Infrared Spectroscopy. The representative FTIR spectra of the four marine sponges extracted (TIM, CR, ConAL, and ConPF) in the $4000-400 \mathrm{~cm}^{-1}$ wavenumber regions are presented in Figure 3. The main bands are labeled in the figure and are described in Table 2. The FTIR spectra of marine sponge extracts are relatively complex and comprise several bands corresponding not only to collagen chemical groups but also probably to other 


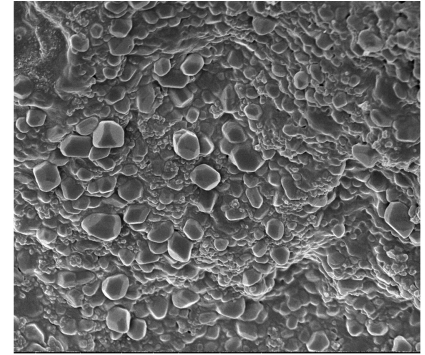

a)

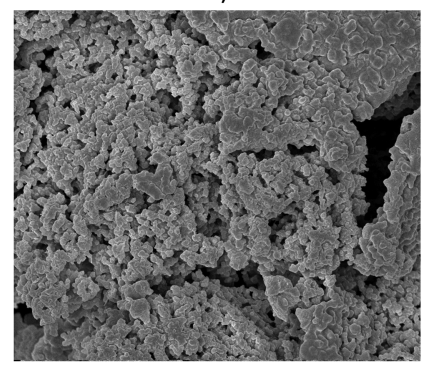

c)

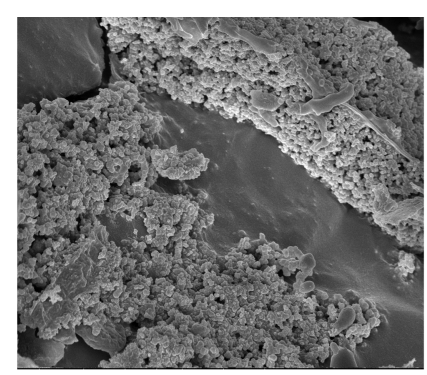

b)

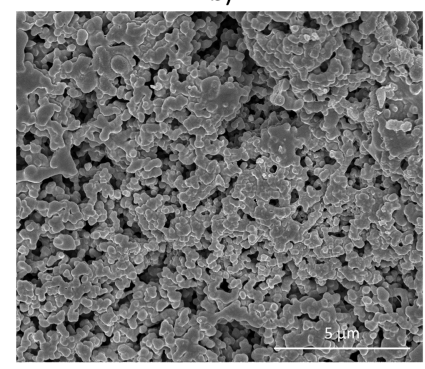

d)
Figure 2. SEM images of the marine sponge collagen/gelatin extracts of (a) TIM, (b) CR, (c) ConAL, and (d) ConPF. Bar $=5 \mu \mathrm{m}$.

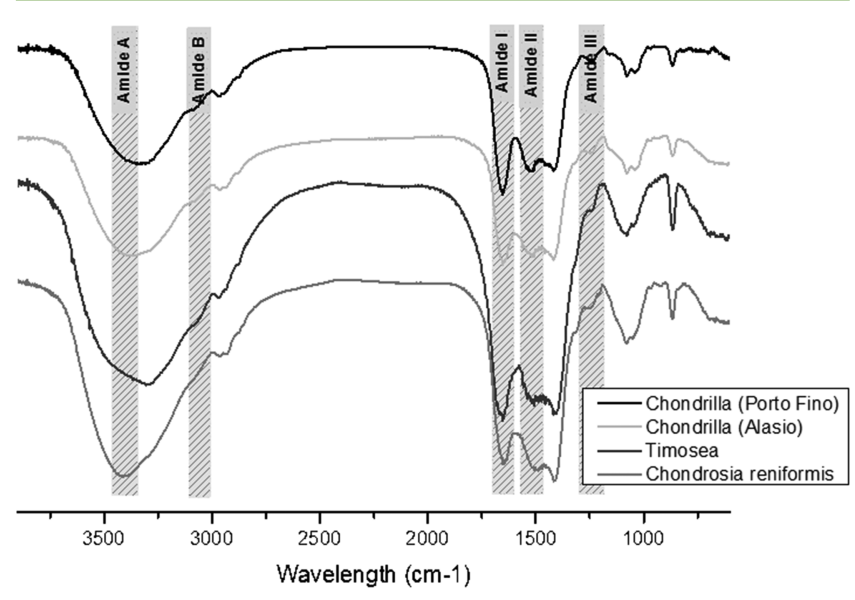

Figure 3. Fourier transform infrared spectra of of the marine sponge collagen/gelatin extracts.

proteins, lipids carbohydrates, and nucleic acids, as shown in Figure 3.

Fourier transform infrared spectra of collagen/gelatin extracted from Thymosia sp., Chondrosia reniformis, and Chondrilla nuculla (Alasio and Portofino) marine sponges had great similarity to each other, which suggested their chemical compositions were relatively similar. The FTIR spectra of different collagen/gelatin contained several bands representing amide $\mathrm{A}$, amide $\mathrm{B}$, amide I, amide II, and amide III, which were similar to those collagen/gelatin from other marine sources reported in the literature. ${ }^{2,28}$ The amide A band is generally associated with the $\mathrm{N}-\mathrm{H}$ stretching vibration and shows the existence of hydrogen bonds ${ }^{28}$ and in our extracts was found at $3425 \mathrm{~cm}^{-1}$. The amide B band was observed at 3283, 3277, 3294, and $3294 \mathrm{~cm}^{-1}$ for TIM, CR, ConAL, and ConPF, respectively, which represents the asymmetrical stretch of $\mathrm{CH}_{3}{ }^{4}$

The amide I band, associated with stretching vibrations of the carbonyl groups $(\mathrm{C}=\mathrm{O}$ bond $),{ }^{29}$ was observed at 1653 , 1644,1647 , and $1653 \mathrm{~cm}^{-1}$ for TIM, CR, ConAL, and ConPF, respectively. The amide II band appeared at $1522 \mathrm{~cm}^{-1}$ for all extracts and is a result of the $\mathrm{N}-\mathrm{H}$ bending vibration coupled with $\mathrm{C}-\mathrm{N}$ stretching vibration. ${ }^{28}$ Amide III was observed at $1240,1249,1240$, and $1242 \mathrm{~cm}^{-1}$ for TIM, CR, ConAL, and ConPF, respectively. Furthermore, the presence of the amide III ( $\mathrm{C}-\mathrm{H}$ stretching) observed by IR absorption suggests the helical structure of the collagen/gelatin extracted. ${ }^{428}$ The marine collagen/gelatin extracted with $\mathrm{CO}_{2}$ acidic water showed a secondary structure.

Circular Dichroism. The circular dichroism spectra (CD) of the four marine sponges extracted (TIM, CR, ConAL, and ConPF) in the wavelength range of $180-260 \mathrm{~nm}$ are shown in Figure 4. CD spectra of the collagen/gelatin controls (collagen

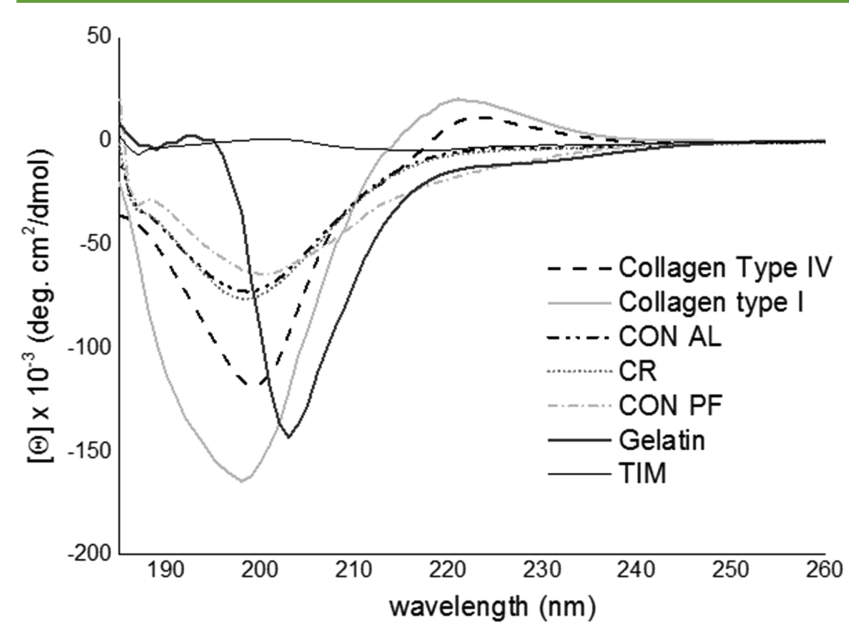

Figure 4. CD spectra of the marine sponge collagen/gelatin extracts measured at room temperature.

Table 2. General Peak Assignments of FTIR Spectra Consist of Marine Sponge Collagen/Gelatin Extracts

\begin{tabular}{|c|c|c|c|c|}
\hline ConPF & ConAL & TIM & $\mathrm{CR}$ & region peak assignments \\
\hline 3425 & 3425 & - & 3425 & amide $\mathrm{A}: \mathrm{N}-\mathrm{H}$ stretching (in proteins) \\
\hline 3294 & 3294 & 3283 & 3277 & $\mathrm{~N}-\mathrm{H}$ stretching when involved in hydrogen bonding \\
\hline 3082 & 3085 & 3076 & 3080 & amide $\mathrm{B}: \mathrm{CH}_{3}$ asymmetric stretching \\
\hline 2934 & 2931 & 2929 & 2925 & amide $\mathrm{B}: \mathrm{CH}_{2}$ asymmetric stretching \\
\hline 2870 & 2873 & 2873 & 2873 & $\mathrm{CH}_{3}$ asymmetric bending \\
\hline 2835 & - & - & 2853 & $\mathrm{CH}_{3}$ symmetric stretching \\
\hline 1653 & 1647 & 1653 & 1644 & amide $\mathrm{I}$ : $\mathrm{C}=\mathrm{O}$ stretching (in proteins) \\
\hline 1522 & 1522 & 1522 & 1522 & amide II: $\mathrm{N}-\mathrm{H}$ bending \\
\hline 1242 & 1240 & 1240 & 1249 & amide III: $\mathrm{C}-\mathrm{H}$ stretching \\
\hline 1078 & 1075 & 4080 & 1080 & $\mathrm{PO}_{2}$ symmetric stretching \\
\hline 1034 & 1034 & 1046 & 1040 & $\mathrm{C}-\mathrm{O}-\mathrm{H}$ from carbohydrates \\
\hline
\end{tabular}


type I from bovine and collagen type IV from human placenta) present two peaks, a positive peak at $221 \mathrm{~nm}$ and a negative peak at $192 \mathrm{~nm}$. This is a characteristic profile of the collagen triple helix. ${ }^{26}$ On the other hand, gelatin, used as a control, and the extracted material from ConAL, ConPF, and CR have positive peaks $(220 \mathrm{~nm})$ that are absent, suggesting the existence of random coils. ${ }^{25}$ The negative peak of the extracted materials is present close to $192 \mathrm{~nm}$, around the value of the negative peak for collagen type IV. A similar profile was obtained by Zhang et al. ${ }^{23}$ in a study with collagen from bovinelimed split wastes, called collagen hydrolysate. In the case of TIM, the CD spectra is not conclusive due the presence of other peaks that may suggest the presence of others compounds.

Thermal Transition Temperature. The denaturation temperature of collagen/gelatin was determined by differential scanning calorimetry. The marine sponge collagen/gelatin extracted had different denaturation temperatures $\left(T_{\mathrm{d}}\right)$ depending on the source (Figure 5 and Table 3 ). The $T_{d}$ of TIM

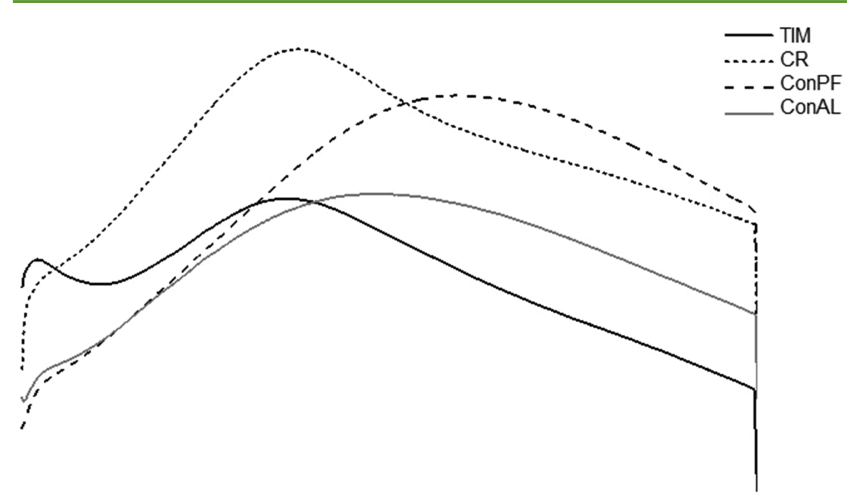

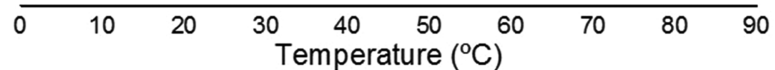

Figure 5. DSC thermogram of marine sponge collagen/gelatin extracts.

Table 3. Denaturation Temperature of the Different Sponge Extracts

\begin{tabular}{cc} 
source & dehydrated samples, $T\left({ }^{\circ} \mathrm{C}\right)$ \\
Thymosea sp. $^{a}$ & 31.02 \\
Chondrosia reniformis $^{a}$ & 30.48 \\
Chondrilla nuculla $^{(\text {Alasio) }}{ }^{a}$ & 38.93 \\
Chondrilla nuculla $^{(\text {Portofino }}{ }^{a}$ & 50.05 \\
${ }^{a}$ Onset point determination. & \\
\hline
\end{tabular}

$\left(31.02{ }^{\circ} \mathrm{C}\right)$ and $\mathrm{CR}\left(30.48{ }^{\circ} \mathrm{C}\right)$ are similar, but the $T_{\mathrm{d}}$ values of ConPF $\left(50.05{ }^{\circ} \mathrm{C}\right)$ and ConAL $\left(38.93{ }^{\circ} \mathrm{C}\right)$ show higher values. Interestingly, comparing the $T_{\mathrm{d}}$ of Chondrilla nuculla, the species cultivated in aquaculture (Alassio) to the one harvested in the wild (Portofino) present different values. The value observed for ConPF is the higher reported in the literature as far as we know. The TIM and CR denaturation temperatures are near collagen type IV from human placenta $\left(28.5^{\circ} \mathrm{C}\right)$. The $T_{\mathrm{d}}$ of the collagen/gelatin extracted from the marine sponges, depending on the source, was close to the other marine sources like muscle of carp $\left(32.50{ }^{\circ} \mathrm{C}\right)$ and Japanese sea bass $(30.00$ ${ }^{\circ} \mathrm{C}$ ) and also calf skin collagen $\left(40.00{ }^{\circ} \mathrm{C}\right)$ as reported in the literature. Nevertheless, this comparison should be carefully made because the scan-rate used in the calorimetric analysis is susceptible of influencing the temperature peak. ${ }^{29}$ The results suggest that intramolecular hydrogen bonds stabilizing the triple helix structure of collagen might be disrupted to some levels, mainly due to the repulsion of collagen molecule in acidic solution. This phenomenon was observed by different authors in extraction of collagen in various marine sources. $^{4,7,26,30}$

Amino Acid Analysis. The imino acid content of proline and hydroxyproline has been correlated with thermal denaturation temperature of marine origin collagen. ${ }^{26,31,35}$ The amino acid composition for the four marine sponges collagen/gelatin extracted was thus determined. The amino acid composition of collagen/gelatin from TIM, CR, ConAl, and ConPF had similar amino acid profiles between them and are presented in Table 4.

Table 4. Amino Acid Composition of Different Sponge Extracts (residues/1000 residues)

\begin{tabular}{ccccc} 
amino acid & TIM & CR & ConAL & ConPF \\
Ala & 101 & 118 & 118 & 113 \\
Thr & 78 & 58 & 61 & 69 \\
Ser & 61 & 59 & 33 & 30 \\
Glu & 117 & 60 & 89 & 85 \\
Gly & 149 & 235 & 239 & 237 \\
Asp & 69 & 66 & 48 & 43 \\
Cys & 5 & 3 & 3 & 4 \\
Val & 29 & 40 & 25 & 26 \\
Met & 4 & 6 & 3 & 2 \\
Ile & 11 & 16 & 9 & 10 \\
Leu & 26 & 22 & 20 & 22 \\
Tyr & 3 & 4 & 7 & 7 \\
Phe & 17 & 15 & 11 & 9 \\
Lys & 30 & 19 & 18 & 16 \\
His & 2 & 6 & 4 & 5 \\
Lys & 22 & 27 & 24 & 21 \\
Arg & 36 & 33 & 39 & 33 \\
Ohpro & 81 & 60 & 83 & 93 \\
Pro & 160 & 151 & 166 & 175 \\
imino acid & 241 & 211 & 249 & 268 \\
\hline
\end{tabular}

Comparing these results with other collagen/gelatin compositions from marine sources, $4,6,7,26,32,36$ we observed an analogous behavior. Collagen is composed by a triple helical sequence of amino acid repeat, (Gly-Pro-Hyp)n, ${ }^{26}$ the most abundant of which is glycine (Gly). This was observed in all extracts where the amounts of $149,235,239$, and 237 total amino acid residues per 1000 residues were determined. Considering the imino acid content (Proline (Pro) + hydroxiproline (Hyp)), the results show values around $\sim 240$ total amino acid residues per 1000 residues, which was slightly higher than in the case of others marine sources ${ }^{1,4,8,26,28}$ and can also justify the higher values of denaturation temperatures. The imino acid contributes to the formation and stabilization of cross-links in the collagen. ${ }^{35}$ The alterations in imino acid content are associated with the different living environments, particularly the temperature of the habitat. ${ }^{28}$

Isoeletric Point Determination. Isoelectric point is an important parameter of proteins because it is related with amino acid content. ${ }^{25}$ All the samples present a similar behavior, showing an isoelectric point around $\mathrm{pH} 8$, in the basic range due to the acidic conditions of the extraction, because this maintained intact the amide residues. ${ }^{25}$ This observation has been reported by Swatschek for collagen 
extracted from Chondrosia reniformis, who indicates an isoelectric range between 6.5 and 8.5. ${ }^{1}$ The titration curves show a flattening area at $\mathrm{pH} 6$ that eventually levels off at $\mathrm{pH} 2$. The behavior of the extracts present a second critical point noted at $\mathrm{pH} 5$, common to the four samples of collagen/gelatin. Highberger et al. $^{3}$ in 1939 reported the existence of two different critical points in the $\mathrm{pH}$ mobility of collagen and gelatin, corresponding to a $\mathrm{pH}$ of 4.7 and 7.7, respectively. Our observations are in agreement with the finding herein reported and may suggest the presence of a mixture between collagen and gelatin in the extracts.

Molecular Weight Determination. The molecular weight of the extracts was determined by size exclusion chromatography (GPC-SEC). The molecular weight of a substance, particularly a polymer, is a key chemical characteristic that can dramatically influence the material mechanical performance, particularly the viscosity and rheological behavior. In this sense, size exclusion chromatography was used to determine the number-average molecular weight $\left(M_{\mathrm{n}}\right)$ and weight-average molecular weight $\left(M_{\mathrm{w}}\right)$ for the four different collagens extracted (Table 5).

Table 5. $M_{\mathrm{n}}$ and $M_{\mathrm{w}}$ of Different Sponge Extracts ${ }^{a}$

\begin{tabular}{lcc}
\multicolumn{1}{c}{ sample } & $M_{\mathrm{n}}(\mathrm{kDa})$ & $M_{\mathrm{w}}(\mathrm{kDa})$ \\
Thymosea sp. & $48.98( \pm 10.63)$ & $155.40( \pm 20.42)$ \\
Chondrosia reniformis & $60.57( \pm 15.73)$ & $208.92( \pm 14.96)$ \\
Chondrilla nuculla (Portofino) & $34.29( \pm 6.52)$ & $112.77( \pm 12.60)$ \\
Chondrilla nuculla (Alassio) & $42.02( \pm 9.76)$ & $110.59( \pm 8.75)$ \\
${ }^{a}$ Standard deviations are in parentheses. & \\
\hline
\end{tabular}

Higher $M_{\mathrm{n}}$ and $M_{\mathrm{w}}$ were obtained in collagen/gelatin extracted from Chondrosia reniformis with 60.57 and $208.92 \mathrm{kDa}$, respectively. The molecular weight of the extracts is similar to the one of collagen/gelatin extracted from other marine sources, such as eel fish skin $(\sim 95 \mathrm{kDa} / \sim 210 \mathrm{kDa}),{ }^{4}$ skin of strip catfish $(\sim 26 \mathrm{kDa} / \sim 95 \mathrm{kDa}),{ }^{11}$ and calf skin collagen and skin of largefin longbarbel catsfish $(\sim 116 \mathrm{kDa} / \sim 200 \mathrm{kDa}){ }^{32}$ Zhang et al. ${ }^{25}$ reported a molecular weight of $\sim 50 \mathrm{kDa}$ for collagen hydrolysate derived from bovine-limed split wastes. The values of the molecular weight reported in the literature are very wide. This is mostly due to the fact that the extraction processes have a high impact on the final extracts. The result of the molecular weight of collagen/gelatin extracted from marine sponges by $\mathrm{CO}_{2}$ acidic water at room temperature demonstrated that they could be used as appropriate materials for biomaterial applications.

In Vitro Cytotoxicity Studies. The cytotoxicities of the four different collagen/gelatin extracts obtained were evaluated in accordance with the protocol described in ISO/EN 10-993. ${ }^{27}$ The viability of the cells cultured in a tissue culture plate in the presence of the collagen/gelatin was determined as a function of the cells cultured in the DMEM culture medium. Figure 6 presents the cell viability after $72 \mathrm{~h}$ in contact with the material. The obtained results were compared to cell growth on the tissue culture plate in the absence of sponge extract, as positive control, and latex, which was used as negative control.

The results show that collagen/gelatin extracted from Chondrosia reniformis and Chondrilla nuculla (Alassio and Portofino) do not compromise the metabolic activity of the cells. On the contrary, cell viability is higher than $100 \%$, which indicates an increase in the metabolic activity of the cells in the presence of this material. The only exception was the extract from Thymosia sp. Even though $82 \%$ of the obtained extract

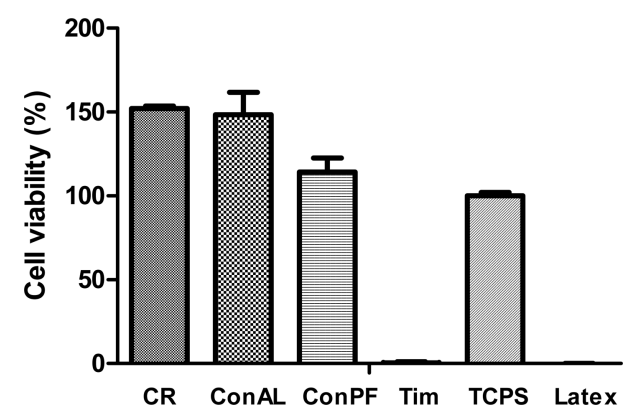

Figure 6. Cytotoxicity screening of the different extracts from marine sponges. Latex extract and standard culture medium (TCPS) were used as positive and negative controls, respectively.

was quantified to be collagen/gelatin, there may be some cytotoxic compounds in the extract responsible for the results obtained. In fact, marine sponges are widely recognized as a marine source of cytotoxic compounds with potential antitumoral interest. ${ }^{33,34,37,38}$ Further purification steps in this case would be required to overcome the toxicity observed.

\section{CONCLUSIONS}

The extraction of sponge origin collagen/gelatin with high pressure carbon dioxide-acidified water was successfully achieved. The proposed methodology allows an extraction of nearly $50 \%$ of the collagen/gelatin content of the sponges tested, representing an increase of more than $30 \%$ over conventional acid extractions using dilute acetic acid solutions. The extracted material was confirmed to be a mixture of collagen and gelatin by different physical and chemical analysis techniques. Cytotoxicity behavior demonstrated that the collagen/gelatin obtained is in most cases noncytotoxic, with the exception of collagen/gelatin extracted from Thymosea sp. The results presented suggest that sponge collagen extracted with water acidified by carbon dioxide is a promising material for biomedical applications.

\section{AUTHOR INFORMATION}

\section{Corresponding Author}

*E-mail: aduarte@dep.uminho.pt.

\section{Notes}

The authors declare no competing financial interest.

\section{ACKNOWLEDGMENTS}

The authors are grateful for financial support of FCT through Grant EXP/QEQ-EPS/0745/2012, SWIMS (Subcritical Water Isolation of compounds from Marine Sponges). The funding from the European Union Seventh Framework Programme (FP7/2007-2013) under grant agreement numbers REGPOTCT2012-316331-POLARIS and KBBE-2010-266033 (project SPECIAL), as well as from ERDF under the project "Novel smart and biomimetic materials for innovative regenerative medicine approaches" RL1-ABMR-NORTE-01-0124-FEDER000016), cofinanced by North Portugal Regional Operational Programme (ON.2, O Novo Norte), under the National Strategic Reference Framework (NSRF) are also gratefully ackowledged. The authors are also truly thankfull to Prof. Micha Ilan (Tel Aviv University, Israel), Dr. Ronald Osinga (Porifarma, The Netherlands), Dr. Antonio Sarà and Dr. Martina Milanese (Studio Associato GAIA, Italy), and Dr. 
Joana Xavier (University of Azores) for the kind offer of marine sponges samples.

\section{REFERENCES}

(1) Swatschek, D.; Schatton, W.; Kellermann, J.; Kreuter, J. R. Eur. J. Pharm. Biopharm. 2002, 53, 107-113.

(2) Silva, T. H.; Duarte, A. R. C.; Moreira-Silva, J.; Mano, J. F.; Reis, R. L. In Biomimetic Approaches for Biomaterials Development; Mano, J. F., Ed.; Wiley-VCH: Weinheim, 2012.

(3) Highberger, J. H. J. Am. Chem. Soc. 1939, 61, 2302-2303.

(4) Veeruraj, A.; Arumugam, M.; Ajithkumar, T.; Balasubramanian, T. J. Mater. Sci.: Mater. Med. 2012, 23, 1729-1738.

(5) Meena, C.; Mengi, S. A.; Deshpande, S. G. Proc. Indian Acad. Sci. (Chem. Sci.) 1999, 111, 319-329.

(6) Hayashi, Y.; Yamada, S.; Yanagi Guchi, K.; Koyama, Z.; Ikeda, T. In Advances in Food and Nutrition Research; Kim, S.-K., Ed.; Academic Press: New York, 2012; Vol. 65, pp 107-120.

(7) Addad, S.; Exposito, J. Y.; Faye, C.; Ricard-Blum, S.; Lethias, C. Mar. Drugs 2011, 9, 967-983.

(8) Friess, W. Eur. J. Pharm. Biopharm. 1998, 45, 113-136.

(9) Lee, C. H.; Singla, A.; Lee, Y. Int. J. Pharm. 2001, 221, 1-22.

(10) Kittiphattanabawon, P.; Benjakul, S.; Visessanguan, W.; Kishimura, H.; Shahidi, F. Food Chem. 2010, 119, 1519-1526.

(11) Singh, P.; Benjakul, S.; Maqsood, S.; Kishimura, H. Food Chem. 2011, 124, 97-105.

(12) Addad, S.; Exposito, J. Y.; Faye, C.; Ricard-Blum, S.; Lethias, C. Mar. Drugs 2011, 9, 967-983.

(13) Zhang, A. W. F.; Li, Z.; He, S.; Shao, L. Food Nutr. Sci. 2011, 2, 818-823.

(14) Takeshi; Suzuki, N. Food Chem. 2000, 68, 277-281.

(15) Nagai, T.; Yamashita, E.; Taniguchi, K.; Kanamori, N.; Suzuki, N. Food Chem. 2001, 72, 425-429.

(16) Lee, K.-j.; Park, H.; Kim, Y.; Park, J.; Yoon, H. J. Korean Soc. Appl. Biol. Chem. 2009, 52, 221-226.

(17) Song, E.; Yeon Kim, S.; Chun, T.; Byun, H.-J.; Lee, Y. M. Biomaterials 2006, 27, 2951-2961.

(18) Pozzolini, M.; Bruzzone, F.; Berilli, V.; Mussino, F.; Cerrano, C.; Benatti, U.; Giovine, M. Mar. Biotechnol. 2012, 14, 281-293.

(19) Heinemann, S.; Ehrlich, H.; Douglas, T.; Heinemann, C.; Worch, H.; Schatton, W.; Hanke, T. Biomacromolecules 2007, 8, 34523457.

(20) Kreuter, J.; Muller, W.; Swatschek, D.; Schatton, W.; Schatton, M. U.S. Patent US20030032601 A1, 2003.

(21) Parenteau-Bareil, R.; Gauvin, R.; Berthod, F. Materials 2010, 3, $1863-1887$.

(22) Pacak, C. A.; Powers, J. M.; Cowan, D. B. Tissue Eng., Part C 2011, 17, 879-885.

(23) Wu, C.-H.; Chai, H.-J. U.S. Patent US20070231878 A1, 2007.

(24) Etherington, D. J. Ann. Rheum. Dis. 1977, 36, 14-17.

(25) Zhang, Z. K.; Li, G. Y.; Shi, B. J. Soc. Leather Technol. Chem. 2006, 90, 23-28.

(26) Slocum, R.H.; Cumings, J.G. In Hommes, F.A., Ed.; Techniques in Diagnostic Human Biochemical Genetics, 1st ed.; Wiley Liss: New York; 1991, pp 87-126.

(27) ISO 10993-5:1999. Biological Evaluation of Medical Devices. Part 5: Tests for in Vitro Cytotoxicity; International Organization for Standardization (ISO): Geneva, Switzerland, 2009.

(28) Berg, A.; Eckmayer, Z. U.S Patent US4363760 A, 1982.

(29) Pallela, R.; Bojja, S.; Janapala, V. R. Int. J. Biol. Macromol. 2011, 49, 85-92.

(30) Veeruraj, A.; Arumugam, M.; Balasubramanian, T. Process Biochem 2013, 48, 1592-1602.

(31) Payne, K. J.; Veis, A. Biopolymers 1988, 27, 1749-1760.

(32) Muyonga, J. H.; Cole, C. G. B.; Duodu, K. G. Food Chem. 2004, $85,81-89$.

(33) Davoodi, J.; Wakarchuk, W. W.; Surewicz, W. K.; Carey, P. R. Protein Sci. 1998, 7, 1538-1544.

(34) Ahmad, M.; Benjakul, S. Food Chem. 2010, 120, 817-824.
(35) Berisio, R.; Granata, V.; Vitagliano, L.; Zagari, A. J. Am. Chem. Soc. 2004, 126, 11402-11403.

(36) Zhang, M.; Liu, W.; Li, G. Food Chem. 2009, 115, 826-831.

(37) Proksch, P.; Putz, A.; Ortlepp, S.; Kjer, J.; Bayer, M. Phytochem Rev. 2010, 9, 475-489.

(38) Zovko, A.; Viktorsson, K.; Lewensohn, R.; Kolosa, K.; Filipic, M.; Xing, H.; Kem, W. R.; Paleari, L.; Turk, T. Mar. Drugs 2013, 11, 2574-2594. 